\title{
Más reformas en la Administración, ¿para qué?
}

\section{Antonio Ramiro Sánchez *}

Pretendo en este artículo, elaborado con posiciones sociológicas y no jurídicas, y con evidente tono coloquial, describir libremente un conjunto de reflexiones que pretenden situarse junto a las corrientes renovadoras sobre la agestión pública. de los países avanzados. Intentaré, básicamente, contribuir al pensamiento crítico desde y hacia dentro de la propia Administración Pública, de la que formo parte, para suscitar voluntades favorables a la ugestión del cambio (en principio, dicho así en abstracto, aunque con la intención de que sean los propios lectores los que piensen cómo traducirlo a la práctica) de nuevas reformas en las administraciones que, como sostengo en el artículo, aún quedan por realizar.

¿Lo único permanente es el cambio", decía Heráclito, y, vitalmente, algo similar ocurriría con las organizaciones «vivas", integradas por personas, con relaciones de comunicación que las mueven, que deben cambiar para no perecer. Con actitud análoga podría afirmarse que tener la disposición a debatir respecto de todo lo público, a nuestro juicio, es imprescindible y, cómo no, positivo para promover reformas en la Administración, pues eso nos permitirá confrontar públicamente sobre sus contenidos, tanto conceptuales como los evidenciados en nuestra práctica diaria, con lo que se estaría, en cierto modo, contribuyendo a la transformación de nuestras organizaciones públicas. Pienso que no hay que rehuir debates, sino propiciarlos, y respecto de la Administración, precisamente, lo que se echa en falta es debatir más con la sociedad sin tabúes ni mixtificaciones y no sólo entre expertos. Para ello, disponer de argumentos propios, y poder racionalizarlos, confrontarlos con otras personas, y aceptar aquellos otros que nos convenzan más que los nuestros, no sólo sería necesario sino que tendría un gran potencial para facilitar las mejores decisiones a adoptar, en su caso.
Conociendo la tradicional gestión de las inercias que se cultiva en las grandes aburocracias, la cultura de la pasividad, de la aceptación acrítica de los procedimientos y modelos de conducta heredados (hacer las cosas porque siempre se hicieron así), la escasez de tiempos para la reflexión directiva, ¿qué nos impele a cuestionar si caben más reformas en las administraciones públicas?

\section{La necesidad de reformas}

Un tema recurrente de los últimos años en algunos discursos políticos, sindicales o mediáticos, es la necesidad de la reforma ${ }^{1}$ (o reformas) de las administraciones públicas, según su ámbito territorial, aunque se reconozcan los avances experimentados en los últimos años por algunas de ellas. Comprobar cómo en otros países, suele ponerse el ejemplo de Italia, a pesar de largos períodos de inestabilidad política y supuestos -desgobiernos ", la maquinaria burocrático-administrativo-gestora sigue funcionando como si no sucediese nada en el ámbito político, alienta el debate sobre la profesionalización ${ }^{2}$ de la Administración, en la medida que ésta, a pesar de los legítimos avatares políticos, no paraliza su actividad que, a la postre, consiste en la implementación de las políticas públicas formuladas desde el nivel político gobernante elegido democráticamente por los ciudadanos. 
Es verdad que las reformas se connotan con un amplio abanico de adjetivos que incluyen no sólo las legales. Es obvio que se han promovido variadas reformas en nuestro país, y que los Gobiernos y Parlamentos autonómicos han decidido en los últimos 15 años numerosas reformas legales administrativas. También, desde el Gobierno central y respecto de la Administración General del Estado (AGE) han visto la luz algunas de ellas muy significativas ${ }^{3}$, especialmente en este último año 1997 y ya se anuncia otro gran cambio normativo con el Estatuto de la Función Pública ${ }^{4}$. Por tanto, en las Comunidades Autónomas y con gobiernos de distinto signo, se ha procurado cambiar (modificar, adaptar, innovar, renovar), al menos desde la Ley, aspectos sustantivos de organización y funcionamiento de las "burocracias", y, ciertamente también, con el actual Gobierno del PP se están dando pasos sustanciales ' en las modificaciones (reformas) legislativas que hagan posible las otras (imprescindibles) reformas también por desarrollar, las de las actitudes y comportamientos, las de las prácticas de funcionamiento real, las que atañen fundamentalmente al desempeño profesional de directivos y empleados públicos.

Así pues, son importantes las recientes reformas, y a nuestro modo de ver y para lo que en este artículo se defiende, sobre todo porque se ha diseñado un nuevo modelo periférico de la Administración del Estado, se han establecido algunos nuevos y muy relevantes principios de organización y funcionamiento de la $\mathrm{AGE}$, se ha delimitado con mayor claridad el ámbito competencial de los niveles políticos y directivos, y se marcan pautas de la prestación y gestión de servicios al ciudadano que hacen más posible, desde la Norma, la consecución de una Administración más moderna que utilice, en sentido amplio, innovadoras tecnologías de gestión que suponen nuevas aportaciones reformadoras para la tradicional cultura burocrática.

Ahora bien, ¿seguirá siendo un recurso referencial para la opinión pública o para los líderes de opinión hablar de la reforma de la Administración?, ¿conocerán los ciudadanos o los medios de comunicación que conforman su opinión los avances producidos, más allá del cambio de denominación de los Gobernadores Civiles?, ¿son conscientes los funcionarios de la potencialidad por explorar de las reformas legislativas producidas?; en este artículo no entraremos a dar respuestas sobre ello, ni abordaremos las modificaciones legales realizadas o aquellas otras pendientes de materialización y que sean precisas. Nos interesa más explicar que, como conocen fundamentalmente los funcionarios públicos, las culturas y las prácticas de gestión, las actitudes y los comportamientos cotidianos en el desarrollo de la función pública, el trabajo diario y la atención al ciudadano, no se modifican sustancialmente, o no sólo, por la ley ${ }^{6}$.

Las reformas son una necesidad para la adaptación de las organizaciones públicas a la llamada ssociedad de la información. (y del acceso al conocimiento) muy diferente tanto a la decimonónica como a la de hace relativamente pocos años, y para ajustar (y re-inventar) el paradigma burocrático weberiano a uno nuevo que contemple los tremendos cambios sociales y económicos ocurridos a lo largo de este siglo, y, en consecuencia, para la adaptación y modemización de la Administración Pública a entomos y condiciones de trabajo diferentes; dicho así: parecería "políicamente correcto y asumido desde planos teóricos, otra cosa es que en la práctica cueste avanzar lo suficiente en la planificación de una gestión del cambio, real y cotidiano, al mismo o a similar ritmo que imprimen los cambios sociales.

Empero, ¿esa necesidad de reformas está concretada social o mediáticamente?: analicemos una muestra, sin pretensiones de rigor metodológico.

A nuestro modo de ver, hay que comenzar por evidenciar públicamente el hecho de que los funcionarios o empleados públicos no son ni están pasivos ani son personas que no tengan pensamiento propio" ${ }^{7}$, a pesar de todos los estereotipos que circulan por ahí, ocupen el puesto que ocupen, frente a los procesos de cambio o de reformas administrativas. Existen muchos directivos ${ }^{8}$ y empleados públicos que desean participar y colaborar en la transformación de la Administración Pública, renovándola, y mejorar el funcionamiento de los servicios públicos actuales.

En relación con los flujos de ideas ${ }^{9}$ que, cotidianamente, se produce entre tantos empleados públicos (más de dos millones en toda España), referidos a lo que ellos "ven" mal y desearian que acambiase, nos gustaría recoger en estas líneas, aunque con osado atrevimiento sociológico, algunas de aquellas ideas.

Muchos tenemos la impresión de que un buen porcentaje de esos dos millones de servidores públicos, incluidos lógicamente los directivos y altos funcionarios, sí creen (otra cuestión sería conocer su grado de escepticismo) en la necesidad de determinadas reformas, y aunque con desiguales grado y concreción de las posibles medidas a tomar, seguramente, sí conocen el funcionamiento interno de las Administraciones, cuyas claves aconsejan tales reformas; conocer sus razones, probablemente, ofrecería "señales. a los posibles ereformadores" respecto a la forma de abordar, gradualmente pero de forma constante y proyectada en el tiempo, el proceso de transformación necesario en las administraciones públicas ${ }^{10}$.

Sin arrogarme ninguna representación, y sólo como observador de las interioridades administrativas, me atrevería a reproducir lo que cualquiera puede sintetizar como opiniones de los servidores públicos:

- se sienten insatisfechos por la percepción social, mi chas veces negativa, o la mala imagen ciudadana sobre los funcionarios o sobre la prestación de servicios públicos, lo que redunda en la escasa dignificación del servidor público frente a la sociedad, aunque, al mismo 
tiempo, se sientan deseosos de ayudar a mejorar la Administración, en su parte alícuota, para que sirva. a los ciudadanos a los que se debe;

- cuestionan comportamientos, prácticas, culturas, actitudes y conocimientos, que hacen que la gestión pública sea, en muchas ocasiones, anticuada, excesivamente procedimentalista con olvido de los fines o resultados, y poco moderna y no adaptada suficientemente a las nuevas realidades socio-culturales de fin de siglo (en dirección de personas, participación, condiciones de trabajo, técnicas o competencias de gestión, tecnologías utilizadas, etc.);

- piensan sinceramente que el funcionamiento de los servicios y de las diversas administraciones públicas puede mejorarse ostensiblemente y que la sociedad española se merece un cambio positivo significativo en la mejora de los resultados de la prestación de servicios, más acorde con el sistema impositivo existente y el grado de desarrollo democrático o progreso social que hoy tenemos en España;

- siguen creyendo en un cierto determinismo que imposibilita ccambiar sustancialmente la Administración y aunque se abordasen algunos cambios, en el mejor de los casos, piensan que se percibiría escasamente en las prácticas cotidianas por el grueso de los empleados y por los propios ciudadanos;

- consideran que existe un cierto déficit de capacidades directivas que, en muchas organizaciones, podría estar desmotivando a elementos valiosos de las mismas y, generando, en todo caso, una percepción insuficiente de rentabilidad de la Administración y escaso éxito social o de impacto de su gestión, lo cual incidiría en la menor legitimidad del Estado frente a la sociedad;

- estiman incompleta la profesionalización de la Administración, que interpretan, de forma amplia, como no ligar las afinidades políticas a la selección de determinados puestos de trabajo, y por proveerlos en función de la experiencia y probada demostración de la suficiente capacidad y mérito para ocuparlos;

- creen que falta un mayor interés, explícito y coherente, en los diversos ámbitos políticos para promover y liderar las reformas precisas de todas las Administraciones, sin el cual se dificulta la licuación de obstáculos y resistencias al cambio de muchos "grupos de interés. de las propias organizaciones públicas;

- creen que por su condición de funcionarios no tienen privilegios, aunque crean que es posible que se suponga socialmente un "privilegio" poseer una plaza en pro- piedad, un puesto fijo, dadas las condiciones del mercado laboral, pero estiman que esa situación laboral es la garantía que tiene, precisamente, la sociedad para que se les administre el dinero público y se sirvan los intereses generales, desde principios de legalidad, igualdad, seguridad jurídica, transparencia, y objetividad.

¿Se puede considerar, tras lo antes expuesto, que cabe promover más reformas en las administraciones públicas? A mi modo de ver, es evidente que sí, máxime si añadimos otros elementos que concurren en nuestro país, como también sucede en otros países, relativos a la presión social para que las administraciones consigan mejores resultados, disminuyan sus costos, •produzcan o rindan más`, o referidos a los programas de convergencia europea que exigen una mayor optimización de los recursos públicos. Es obvio que habría otras razones para seguir considerando que se precisan más reformas, no tanto legales, en la medida que observemos (y deseemos aprehender de lo estimable de ellas) las nuevas pautas de gestión pública emergentes en la mayor parte de los países de la OCDE, esencialmente relacionadas con el ejercicio de la función directiva en marcos más estrictos de planificación y control de la gestión y de mayor responsabilización por los resultados alcanzados, o dicho de otro modo, se precisan mayores cotas en los niveles de eficacia y eficiencia "del sector público, a fin de que el funcionamiento de las administraciones no se cuestione, ni en términos de magnitudes económicas o socio-laborales ni en términos de legitimidad social. Ello alumbra, probablemente, una de las más importantes líneas reformadoras por desarrollar más intensamente, la de corregir los déficit gerenciales y mejorar los sistemas de dirección o directivos de las administraciones públicas.

\section{2. ¿Trabajamos los servidores públicos para una "empresa" especial?}

El siguiente corpus discursivo se justifica por la «razón de ser de la profesión que, dialécticamente, pretendo desempeñar: la de sservidor públicon. Invito a la acepción de *empresa. en su doble sentido; de un lado, como un empeño, un reto, un compromiso, una gran tarea emprendedora, cuyos objetivos y actitudes deberían compartirse por los distintos actores sociales: partidos políticos, sindicatos, empleados en general, empresarios, usuarios, clientes o ciudadanos; por otro lado, también decimos empresa. con la acepción tradicional de organización empresarial que busca beneficios, connotando con ello lo que en el fondo de las reformas (sobre todo de las referidas a los 
sistemas de dirección y a las técnicas de gestión) nos gustaría que subyaciera, esto es, una nueva mentalidad, una nueva cultura administrativa y organizativa, que considere que la Administración es también una empresa" (mejor sería una organización, o, aún mejor, muchas organizaciones con empleados, recursos económicos, mandatos, objetivos y finalidades) que debe ser rentable socialmente, (metafóricamente los partidos políticos integrarían el Consejo de administración elegido por los socios: la ciudadanía) y para sus propios empleados que somos sus trabajadores. Eso debería interpretarse en el sentido de que a los servidores públicos nos interesa que nuestra empresa . funcione. $y$ tenga "ganancias" (beneficios sociales, es decir, percepción de utilidad democrática, rentabilidad social).

Singular debe ser el interés de los empleados públicos por sentirse identificados con su empresa y con la mejor prestación de servicios a los "clientesn, e interiorizar que para ello es preciso que quienes la dirigen (desde la gerencia pública) profundicen y mejoren los sistemas de dirección, motiven a sus empleados e incentiven el rendimiento de éstos, optimicen el uso de los recursos públicos, busquen cotas mayores en el cumplimiento de objetivos, dirijan a sus empleados en el marco de las tendencias actuales modemas de edirección de personas., y favorezcan nuevos espacios y técnicas de gestión, con los que todos podamos trabajar mejor y rendir más en nuestra organización para la mejor administración del dinero público.

En consecuencia, ruego al lector que no malinterprete el uso del término de empresa. ni se le otorgue otra explicación que la aquí referida; ni mitifiquemos ni copiemos acríticamente la tecnología del conocimiento del sector privado; uno de los retos para acertar en la modemización de la Administración es atinar con el bagaje de la tecnología o técnicas de gestión a emplear, que no deben mimetizarse exactamente de la empresa privada, sino adaptadas inteligentemente a lo que cada vez más denominamos como la agestión pública"; se acertará más si somos capaces de poner en práctica principios (insuficientemente aplicados) de funcionamiento de servicio efectivo y de gestión de calidad de servicios a los ciudadanos, de responsabilidad por la gestión pública, de programación y desarrollo de objetivos y control de la gestión y de los resultados.

En definitiva, acertaremos en las reformas de gestión pública si procuramos la mejor obtención de resultados, cuantitativa y cualitativamente, y un buen uso de los recursos que justifiquen socialmente la necesidad de la ciudadanía de dotarse de organizaciones que administren mejor los instrumentos de vertebración y convivencia social y hagan más rigurosa y eficaz la implementación de las políticas públicas.

Para ese fin, de forma análoga a lo que se instrumentaliza en las mejores empresas privadas, aunque (jatención!) traduciéndolo a las peculiaridades de lo público (que no son pocas), en las organizaciones de la Administración debe evaluarse por los órganos competente la eficacia de los equipos directivos y de los empleados, y, evaluar hasta qué punto se satisfacen, también desde la gestión, las necesidades y demandas e intereses sociales, o cómo hacer que los "clientes" (los administrados, ciudadanos o usuarios) estén satisfechos con el producto o servicio ofrecido; debe, asimismo, tomarse conciencia de que, como en toda empresa, el devenir profesional de un empleado no puede ir separado de forma dispar a su rendimiento, no debe seguir considerándose, ni por la sociedad en su conjunto ni por los servidores públicos, que se haga lo que se haga. no influye en modo alguno en la carrera administrativa o en las relaciones laborales del empleado aludido.

Para ello, se precisa un cambio cultural: huyamos de los maniqueos y no caigamos en responsabilizar en exclusiva a algún colectivo en particular sobre las culpas de los llamados -males. de las administraciones públicas, o sobre a quién le toca coger "el toro por los cuernos" y ahacer lo que haya que hacern para mejorar la situación. El ámbito político de los diversos gobiernos, oposiciones y fuerzas de los distintos Parlamentos, e! ámbito de la gestión, directivos y empleados, fuerzas sindicales, y la participación ciudadana, son elementos que tomados en su conjunto, e interactuando dialécticamente, pueden producir las sinergias precisas para conducir los proyectos de cambio, las reformas, hacia el éxito. Pero, en la cuota parte que como servidores públicos nos toca asumir, no deberíamos inhibirnos y seguir remitiendo a "otros" la responsabilidad de «mejorar"; a veces, por anecdótico que pudiera parecer, el ejemplo indrvidual derivado del mejor desempeño es un elemento que, aunque unitario, contribuirá a reformar las auténticas prácticas de desempeño y gestión.

Con esa perspectiva, nuestro diagnóstico es que tanto los sindicatos, como los partidos políticos, precisan de un explícito y mayor empuje o impulso de la sociedad española y de la mayoría de empleados públicos, que expresarian el deseo y la fuerte demanda social de cambio en las administraciones públicas. Estas demandas no terminan de modelarse o de tomar un perfil nítido reconocible, y ello es preciso para la concreción de los proyectos y las estrategias de cambio. Éstos, en cualquier caso, deben, de forma pedagógica, explicarse y defenderse por las fuerzas políticas y sindicales, de modo que, al mismo tiempo, se contribuya a la mayor democratización y legitimidad social de la Administración y, también, de la acción política y sindical.

En numerosos países ${ }^{12}$ se han abordado distintas estrategias de implementación de los cambios; seguramente no es fácil atinar con las diversas posibilidades, caminos y alternativas para las reformas, para las mejoras continuas, y además no creemos que haya, ni deba haberla, una única salida posible.

Ahora bien, el sentir colectivo que se percibe, internamente de los empleados, y externamente de los expertos del Derecho 
público, de las Ciencias Políticas, del management o de la •gestión pública, es de gran escepticismo, seguramente porque son muchos los que consideran que se ha abusado de propuestas meramente retóricas, con contenidos llenos de lugares comunes pero desprovistos de sustancias tangibles.

Mi opinión, sin embargo, es que, en términos generales, se han hecho los suficientes diagnósticos de los déficit e incapacidades de las organizaciones burocráticas tradicionales, y que donde hay que apuntar es al diseño del modelo hacia el que caminar, eligiendo una buena senda para proseguir las vías reformadoras, y una buena estrategia de cómo gestionar el cambio. Es verdad que cambiar la realidad de la Administración sólo puede rigurosamente llevarse a cabo, por los que ejerzan el liderazgo, de forma valiente, constante y creativa, sabiendo que los necesarios cambios no se consiguen en el cortísimo plazo y que se trata más de proyectos con visión de futuro, que exigen el esfuerzo, el apoyo y el trabajo de todos, con la ilusión de los que tienen vocación y pretenden dignificar el ejercicio de servidores públicos. Las reformas, la modemización en las administraciones, deben pasar de forma relevante por modifcar, por transformar, por re-inventar una enueva gestión pública con técnicas renovadas y precisas de gestión para el mejor funcionamiento de las organizaciones públicas, que deben demostrar a la sociedad que también desde lo público se puede ser útil y eficiente y prestar los mejores servicios y de mayor calidad a la ciudadanía. Al ámbito político le tocaría estimular la renovación de la gestión pública y el perfeccionamiento de la función directiva.

Las reformas, la mejora continua, la formación directiva, las prácticas gestoras, no deben ser pretextos conceptuales para el ejercicio literario o para demostrar quién lo diserta mejor. Las administraciones públicas en España, a pesar de lo efectivamente ya realizado excepcionalmente por algunas organizaciones, no pueden seguir de espaldas a los cambios experimentados en la mayor parte de los países de la OCDE, ni pueden estar en el furgón de cola en la renovación de la gestión pública o en la utilización de los sistemas de gestión que tienen éxito en otras administraciones extranjeras y, por ello, los dirigentes de nuestras administraciones deben definir aquellos conceptos en términos de planes de acción o proyectos de cambio.

Es esa la razón por la que los objetivos de las reformas deberían hacerse explícitos, traducirse en hechos concretos, aunque sean modestos en el tiempo, percibirse como graduales en su consecución y para la transformación de las prácticas directivas, y programados en el espacio temporal, a pesar de las legislaturas, con el mayor consenso que se pueda alcanzar entre los distintos partidos políticos, y con la coordinación y la cooperación entre las diversas administraciones públicas.

En España, de forma constructiva, debemos enriquecernos de las experiencias de unas y otras administraciones, del mun- do y de nuestro país, hayan tenido o no resultados satisfactorios. De la experiencia comparada podremos aprender cómo no errar o mejor acertar. Es probable que de un honesto y constructivo debate público (sin maniqueísmos y sin la utilización de armas arrojadizas) aparezcan muchas más coincidencias que desencuentros entre empleados y directivos públicos, sindicatos, responsables políticos del gobierno o de la oposición, si nos atuviéramos a la coincidencia en los fines que muchas veces son explicitadas en el mismo sentido por todos ellos.

Creo que no sería ilusorio atreverse a afirmar que las reformas son posibles, aunque reconozcamos que los procesos son difíciles, complejos, de extraordinaria envergadura, y acechados de efrancotiradores que, por acción u omisión, no coadyuvan a su éxito. Los caminos de implementar las reformas en las administraciones públicas pueden ser muy diversos, y esa elección, aunque pueda suscitar discusión o discrepancia, competerá más a los decisores políticos, a los que atañe también el mayor impulso para desarrollarlos.

Las reformas, al mismo tiempo, no necesariamente deben significar que haya que abordar todo lo reformable en el mismo iter temporal; las reformas deben contemplar la gradualidad cuantitativa en la definición de proyectos de cambio, abordando microproyectos o pequeñas mejoras de gestión, pausadamente pero de forma estable y segura, y uno tras otro, secuencialmente, pero siempre que estén dentro de la coherencia de un modelo global que haga encajar, a modo de necesario puzzle, una determinada acción con otra decisión que la apuntale y posteriormente con otras ulteriores en la misma línea.

Ciñéndonos a las experiencias, creemos que o se dispone del apoyo del máximo vértice estratégico de los gobiernos que dirigen, desde cada ámbito políico, a las distintas administraciones públicas, o no será posible comenzar, desarrollar y culminar los proyectos reformadores que éstas precisan, siendo mi hipótesis que aquella voluntad política explícita y así percibida sería una condición absolutamente necesaria aunque fuese insuficiente.

Multitud de declaraciones de los diversos agentes sociales expresan la relevancia que tiene el "capital humano" para los procesos de cambio, siendo el mayor riesgo que de tanto sólo verbalizarlo pueda convertirse en un recurso o •latiguillo. retórico. Efectivamente, o se cuenta con los empleados públicos a través del máximo posible de instrumentos para conocer sus opiniones e implicarlos, a través de la participación organizativa, o tampoco obtendrán buenos resultados los procesos reformadores o de cambio. Y contar con los empleados no debe significar aceptar el statu quo inmovilista que, por principio, frene o se resista al cambio; ‘contar con los empleados no es sólo relacionarse con sus representantes sindicales; la responsabilidad de los directivos o de los jefes de las unidades administrativas se ejerce administrando recursos y, también, adirigiendo. a 
persónas, lo cual trasciende la exclusiva anegociación. de las condiciones de trabajo, para conllevar aptitudes de gestión del clima laboral, explicación de proyectos, asignación de tareas y responsabilidades a los subordinados, definición de funciones, orientación para el mejor desempeño, seguimiento y control de las actividades, atención a la formación que se precise, etc., etc.

Mención aparte merecen los directivos públicos. Muchos de los cambios "reales" por implementarse, que no sean meramente nominalistas, dependen de su actuación y liderazgo. En su mano existe una fortísima llave de la implementación de los procesos de cambio. De ahí la importancia que hay que reconocerle a la función directiva.

Sabemos que se han puesto en marcha, o desarrollado con éxito, diversos aunque singulares y pequeños cambios, o iniciativas de mejora y otras medidas modemizadoras en muchas administraciones públicas, algunos desde hace varios años, ya hayan sido en alguna Comunidad Autónoma o en algún Ayuntamiento, pero hay que reconocer que falta todavía mucho por hacer en conjunto, de forma global y relevante para la percepción social, que ha existido mucho voluntarismo en estos últimos años, a veces muchas buenas intenciones, pero ha habido también poca programación para la extensión de la persuasión e interiorización necesarias de los Gestores públicos, de modo que éstos lideraran los cambios en las organizaciones que dirigen.

Es preciso convencer razonablemente, a través de la formación y con el intercambio de experiencias de las que aprender a aprender", que el éxito de muchos cambios en la gestión pública dependerá de cómo se sostengan en el tiempo, de modo que no se vean amenazados por las alternancias políticas, en la medida que, lógicamente, muchos de dichos cambios precisarán de programas a medio y largo plazo, con varios horizontes legislativos El riesgo, en ocasiones, sería correr en exceso, y sólo realizar cambios "aparentes" que justifiquen las acciones gestuales o de apuesta en escena. de los mismos, con desdoro de los resultados, lo que, a la postre, no iría más allá de la asunción de amodas" que, por cierto, hasta ahora han generado no pocas frustraciones en el seno de las organizaciones, lo cual podría haber contribuido a alimentar la inhibición o el escepticismo en la posible emasa crítica favorable a los cambios.

No obstante, creo que los esfuerzos de inversión de los últimos años, en formación o en nuevas tecnologías, no han caído en saco roto $y$ nos hace ser optimistas en la medida que, probablemente, en nuestro país existe ya un suficiente conocimiento, siquiera intuitivo, de las potencialidades de una egestión públican por alumbrar, tanto por parte de los directivos y de los funcionarios de los niveles más elevados, así como de los propios sindicatos y de muchos empleados de los niveles inferiores de las administraciones públicas Es decir, probablemente no se trataría tanto de invertir mucho más en la formación para el cambio cultural, cuanto de formular y desarrollar los adecuados proyectos de cambio organizativo y gerencial.

Desde aquí, al pretender sugerir caminos de avance, no miramos retrospectivamente ni con ánimo de atribuir •culpas* a los que ejercieron el liderazgo en el próximo pasado, ni con intención de paralizarnos en estériles discusiones sobre to que pudo haber sido y no fue, sino para aprender de lo pasado, sintiéndonos, en el porcentaje que nos toque, responsables de lo que no se avanzó, deteniéndonos un momento preciso para analizar las experiencias desde las que partir, enriqueciéndonos de ellas, o para proseguir caminando más de prisa hacia el futuro. Sólo desde la mayor unidad y colaboración de todos los agentes interesados en el cambio será más fácil la consecución del mismo.

\section{3. ¿Por qué no se ha realizado todo lo necesario para las reformas de las Administraciones Públicas en estas últimas décadas?}

Citaré sólo algunas de las causas que, sin ánimo exhaustivo y sin seguir ningún orden prioritario, serían a mi juicio las más importantes para poder explicar el escaso éxito de diversos intentos reformadores de las administraciones públicas de las dos décadas precedentes, algunas de aquéllas sin claro sujeto a quien atribuir la responsabilidad, elemento muy típico de la Administración. En general, por lo que conocemos, tales causas podrían servir, en su conjunto, para explicar tanto lo ocurrido en la Administración General del Estado como en las otras administraciones, la Administración Local o las Administraciones Autonómicas, aunque en estas últimas las causas pudieran tener otros matices y peculiaridades.

Veamos esas causas:

1. La débil formación de muchos dirigentes de las organizaciones públicas y la insuficiente preparación para formular (o transmitir) y hacer que se ejecuten con más rigor determinadas políticas públicas;

2. las agendas de los partidos políticos que no incluían proyectos globales de reforma política y administrativa de las diversas administraciones públicas, y se conformaban con medidas coyunturales o aisladas (cuasi *anecdóticas*) que no iban al fondo de los cambios precisos; 
3. la rápida construcción de los elementos cruciales del Estado del bienestar, con el consiguiente incremento de servicios y funcionarios, lo que ponía en un plano muy ulterior el estudio o las voluntades de reformar las administraciones que tenían que gestionar, precisamente, ese nuevo Estado de bienestar;

4. la integración europea y la necesidad de obtener con rapidez parámetros e indicadores socio-económicos homologables con otras sociedades, lo que hacía poner más el énfasis en buscar indicadores de corto plazo, aunque coyunturales e inestables, que en otros de más largo alcance; por ejemplo, designando nominativamente a funcionarios europeos que en preocuparse por el sistema de selección; es decir, se colocaba en primer plano prioridades no reformadoras sino las típicas incrementalistas;

5. la mixtificación y, a veces, el deslumbramiento de algunas supuestas novedades técnico-gestoras que, al ser implementadas con voluntarismo, generaban mayores fuerzas resistentes a nuevos cambios, por el nivel de fracaso o frustración alcanzados ${ }^{13}$;

6. el desarrollo del Estado de las Autonomías que, al tener que conllevar la creación (o re-creación) de las Administraciones Autonómicas, propiciaba más mantener el modelo existente de Administración del Estado que asumir nuevos proyectos de reformas organizativas o de funcionamiento sobre algo por construir", dando poca importancia, por ejemplo, los diversos gobiemos autonómicos, en general, a la delimitación y adecuación del número de funcionarios a las competencias atribuidas y transferidas, para enfatizar más el crecimiento, no siempre justificado, de un volumen de personal propio y seleccionado en corto espacio de tiempo, sin importar tanto la posible coordinación con la Administración del Estado para optimizar el personal de ésta, en la medida que se fueran transfiriendo nuevas competencias;

7. los "objetivos" (se deduce el supuesto) de los primeros gobiemos de UCD y del PSOE de no asustar. a los empleados públicos con (supuestas) grandes reformas, por lo que "decidieron (es decir, no actuaron) que era mejor no emprenderlas sino tomar algunas medidas que mejorasen la situación heredada (lo que fue más un "parche), sin darle mayor importancia al preciso sostenimiento de algunos cambios en el tiempo o a la transformación real de los modelos de gestión pública;

8. los errores cometidos en un cierto mantenimiento del sistema de botín. (spoil system) focalizado en determinados puestos directivos, lo cual es achacable a las diversas administraciones públicas, con la consiguiente "voracidad incontrolables personalista en la ocupación de muchos puestos clave, sustituyendo a funcionarios valiosos por muchos nuevos acuadros. supuestamente más afines políticamente, que abundantemente no eran lo suficientemente competentes para la obtención de la mejor gestión, lo que a la postre incluso iba en detrimento de la puesta en práctica de las propias políticas públicas;

9. la necesidad de dar tiempo (hoy podría decirse que resultó excesivo) a que se asimilara el anunciado gran cambio (que finalmente resultó pacato y muy insuficiente si nos atenemos a cómo se desarrolló y se aplicó en las prácticas reales) que suponía la Ley 30/84 de «medidas para la reforma de la función pública, lo cual ha ido consolidando una percepción negativa y escéptica sobre lo difícil que es renovar ciertas prácticas de gestión (v. gr. de gestión de personal), y que, entre otras cosas, por citar otro ejemplo, al tratarse de una Ley de -basesn para Comunidades Autónomas y Administración Local, en la práctica, ha sido un obstáculo también para la puesta en marcha de medidas reformadoras en esos niveles de la Administración Pública;

10. la "confusión" entre responsabilidades políticas y administrativas o gestoras (quizás contribuyó la inexperiencia de convivir en democracia) y la ausencia de una cultura generalizada de responsabilidad, lo que a nuestro juicio ha ido en detrimento de la mayor profesionalización del ámbito gestor o directivo, y que explicaría en parte, por ejemplo, algunas conductas reprobables archiconocidas;

11. la opción timorata de los conocidos aplanes ${ }^{14}$ de modernizaciónn de la Administración del Estado (no interiorizados suficientemente por las propias organizaciones públicas al considerar que su impulso y objetivos "venían de fuera.), en lugar de introducir medidas más atrevidas de cambio de cultura y de la mentalidad administrativa, en las que apoyarse para proyectos más ambiciosos de cambios organizativos o normativos;

12. el insuficiente peso competencial del Ministerio designado para liderar o promocionar las reformas o la supuesta modernización, no percibido como referente dominante en sus competencias horizontales por los integrantes de los restantes Departamentos, y la ausencia de voluntad explícita y taxativa de la máxima cúspide política en las decisiones conocidas del Consejo de Ministros ${ }^{15}$ para legitimar (o facilitar su visualización simbólica) acciones coordinadas de reformas o proyectos de cambio interministeriales, que no sucumbieran al peso tradicional de otros ministerios (o de algunos sectores corporativos de los mismos) reacios a los avances en la práctica real, hacia una gestión pública más flexible, singular a la heterogeneidad organizativa de la Ad- 
ministración y más adaptada a las corrientes modernas latentes en otros países;

13. el gran peso de las tradiciones y del conservadurismo administrativo que, en la práctica, frena y obstaculiza en grado sumo los procesos de avance y de reforma ${ }^{16}$;

14. la patrimonialización de la función pública por diversas fuerzas sectoriales que, en la práctica, han obstaculizado las reformas ${ }^{17}$, en ocasiones desvirtuando lo previsto en las leyes;

15. la ausencia de un proyecto global de transformación del paradigma burocrático que hiciera coherentes entre sí los pequeños pasos reformadores a dar, los cuales se estaban dando más con voluntarismo y buena fe que con rigor metodológico en su concepción y gestión ${ }^{18}$;

16. la escasa valentía para sacar a la luz el debate de lo público (no en términos de políicas públicas), y para liderar con transparencia política y administrativa la implicación del conjunto de empleados públicos con los proyectos reformadores que, en el mejor de los casos, sólo se conocía que se estaban estudiando;

17. los déficit de algunos gestores públicos para caminar hacia cualquier dirección reformadora o para interpretar, en claves de acción positiva, los mandatos políticos o legales, explícitos o implícitos, obstaculizando en sus prácticas inmovilistas siquiera el inicio de algunos posibles procesos de cambio ${ }^{19}$;

18. el anquilosamiento de ciertas prácticas sindicales, poco modernizadas y corporativas, en las que estuvo ausente, por inhibición o pasividad, un discurso propio o una toma de postura ante un modelo reformador de la Administración pública, y seguramente también por existir todavía prejuicios negativos y maniqueos sobre la gestión pública y el management (recelo a todo aquello que sonara a eempresa privadan);

19. la falta de elaboración o explicitud de discursos políticos para contrastarlos entre sí (sin tener que recurrir a las insuficiencias de las organizaciones y explicarlas sólo en función de la mala gestión de un partido gobemante), y, en el caso de la gestión pública, de la ausencia de -visiones interpartidarias. susceptibles de asumir colectivamente por los distintos grupos políticos, que pactasen la necesidad de reformar las administraciones públicas, de modo que éstas fuesen un instrumento que sirviera para la implementación de las políticas públicas formuladas legítimamente por uno u otro partido;

20. la gran fuerza de la cultura jurídica (en su versión juridicista.), que en ocasiones ha impedido acciones de cambio que estaban justificadas por una visión más ge- rencial de orientación a resultados, y menos prisionera del excesivo reglamentismo cuyo fin fuese el propio procedimiento;

21. el entorno no favorecedor de una sociedad como la española que históricamente, con razones más o menos justificables por otra parte, no ha legitimado la acción del Estado, ni de su Administración Pública, lo cual no ha ayudado precisamente a la extensión de la cultura gerencialista pública ${ }^{20}$;

22. y, finalmente, a la falta de una clara y auténtica voluntad política y sindical de los que han tenido influencia y poder central, autonómico y local, para atreverse realmente (y no retóricamente) a abordar, con proyectos concretos, la implementación de los cambios, transformaciones y adaptaciones precisas de la Administración Pública a una sociedad, y a unos entornos diferentes, que sí han evolucionado en determinados aspectos a ritmos superiores.

Pero las claves de los proyectos de reformas modernas de las administraciones públicas, de modo que éstas se pongan al servicio del ciudadano a través de la puesta en práctica de las políticas decididas democráticamente en las urnas, a mi juicio, deben ser interpartidarias (y menos partidistas), y deben ir más allá, por mucho que ello pueda ser necesario, de la supresión de cargos, ministerios o de unidades administrativas o de la reducción de algunos gastos corrientes.

No creo que en el resultado de un debate, a condición de que se tenga interés por convenir soluciones, pueda haber demasiados desacuerdos entre los partidos políticos para definir modelos de gestión en las administraciones públicas, y coordinar esfuerzos para implementarlos en un mismo sentido. No debería haber diferencias insalvables en clarificar modelos de gestión o aspectos tales como, por ejemplo, la evaluación de las responsabilidades directivas, la dotación de mejores instrumentos y técnicas de dirección, planificación y gestión pública, el uso de los sistemas de información, la implantación de sistemas de control de gestión y evaluación de resultados por los propios gestores, el diseño de la carrera administrativa y la definición del estatuto del directivo, la programación de la formación que atienda necesidades singulares de cada organización, la búsqueda de la motivación del empleado, la adecuada distribución de competencias entre niveles de administraciones y su no solapamiento, el reparto y redistribución de funcionarios entre Administraciones para optimizar el empleo público y no seguir creciéndose más en unas u otras administraciones públicas, el desarrollo del modelo de Administración territorial, la mejor conceptualización de la descentralización (o divisionalización), la mayor autonomía de gestión de determinados Organismos o Entes Públicos, el adelgazamiento y simplificación de estructuras administrativas, la generalización de una nueva cultura ética 
y de responsabilidad en el servicio público, o cómo hacer más eficiente la gestión y la administración de los dineros públicos.

Es natural pensar que a todos los agentes sociales con capacidad de decisión sobre la Administración les debe interesar resolver cuestiones de Estado y que sean soluciones duraderas y estables. De ello se beneficiaría la propia ciudadanía y, por qué no, los propios empleados públicos, que no estarian tan a menudo en el rojo del huracán. (mediático, sobre todo) cuando se debata sobre la Administración.

No lo tienen fácil los partidos políticos gobemantes, pues los obstáculos para mejorar la gestión y para orientar el cambio cultural hacia nuevos principios de funcionamiento, en las prácticas cotidianas, se repiten de una a otra etapa, con uno y otro partido, y en una y en otra Administración Pública, y las fuerzas resistentes al cambio (naturales a todo tipo de organizaciones) siempre recelan y procuran impedir, como grupos de presión, los avances en profundidad. Ahora bien, de los errores ajenos se podrá sacar mucho provecho y eso debería ayudar a no repetir los habidos en nuestro país en los últimos años.

En todo caso, no importa mucho si es sólo por sla dinámica de los tiempos. o por lo inevitable, por lo que deberían abordarse seriamente proyectos reformadores; importa mucho más el que se tenga la voluntad de sostenerlos en el tiempo, pues modificar las pautas de funcionamiento y de comportamiento de las administraciones públicas, de sus empleados y directivos, es un ejercicio a muchos años vista, lo cual no empecería en absoluto seguir programando y desarrollando el camino reformador.

\section{La necesidad de un} nuevo impulso reformista y de la adopción de medidas inmediatas para mejorar resultados

La situación actual en la organización de las Administraciones Públicas, y por el impacto social de su funcionamiento, me hace creer en la necesidad de un impulso reformista en la manera de funcionar de aquéllas; es preciso profundizar en renovados funcionamientos de la organización administrativa, en los procesos de toma de decisiones, en las instituciones que hacen efectiva la responsabilidad, en los mecanismos de control inter-. no de los propios Gestores, o en los cauces por los que circu- lan las transacciones con la sociedad. Para reforzar la responsabilidad y transparencia de la vida pública habría que pensar, entre otras soluciones, en:

- corregir algunas prácticas políticas con responsabilidad de gobierno, y disminuir el control directo, muchas veces excesivo, sobre la esfera pública no política, lo cual se sigue viendo como un elemento del spoil system al que se tuviere derecho tras una victoria electoral (ello alimenta a la opinión pública, y a los empleados, en cultivar estereotipos decimonónicos y que se persista en creer que cada partido político en su Ayuntamiento, Comunidad o en la Administración del Estado ccoloca a los suyos", cuando, además, muchas veces no es asî);

- superar aún más la confusión entre responsabilidades políticas y las meramente administrativas o gestoras, separando sus esferas decisionales y sus mecanismos de responsabilidad, con la mayor profesionalización de la Administración, a través de una dirección pública profesional, seleccionada con criterios de mérito y capacidad y juzgada (y evaluada en la práctica con rigor por sus órganos superiores) en función de los resultados obtenidos (como además la Ley ya prevé);

- renovar el ordenamiento administrativo, y adaptar normas, procedimientos y técnicas a la realidad heterogénea y dinámica a la que se enfrentan las Administraciones Públicas, dándole mayor autonomía y responsabilidad a los directivos de línea;

- reconducir la utilización instrumental que se hace de las formas privadas para gestionar servicios públicos, y emplearlas cuando se enmarquen en unas reglas estrictas de transparencia y responsabilidad paralelas a la mayor autonomía de gestión.

Las reformas de las administraciones públicas deben contribuir a restaurar la confianza de los ciudadanos en las instituciones y en el propio Estado, al ser su principal instrumento, lo que debe suponer una renovación profunda de las estructuras y procesos que canalizan el ejercicio de los poderes públicos. Toda democracia cuya Administración es sospechosa de clientelismo, comupción o ineficacia ve resquebrajada su legitimidad social.

Es necesario que el funcionamiento de las instituciones infunda confianza y respeto a los ciudadanos. Esto requiere reformas en la organización administrativa, en sus procesos de funcionamiento y en las conductas de sus agentes, que permitan hacer efectiva la responsabilidad de políticos y funcionarios, mediante una mayor transparencia en la vida pública. Algunas de estas reformas ya se han hecho, aunque siempre pueda haber quien defienda que caben otras o mejorar las anteriores, y de algunas medidas legales recientes (como la de la Ley de Organización y Funcionamiento de la Administración General del Estado - LO- 
FAGE-) sólo cabría comenzar a aplicar en las prácticas directivas reales algunos de sus principios de funcionamiento.

De las reformas, de la modernización del sector público depende también, aunque sea en parte, el éxito o el fracaso de nuestro mayor empeño nacional: lograr la convergencia con los niveles de bienestar de los países europeos más avanzados, asegurando un reparto equilibrado de la prosperidad entre todos los ciudadanos y los pueblos de España.

Los empleados públicos, también los directivos públicos, precisamos de nuestro prestigio social, queremos dignificar nuestra función pública, queremos ejercer de servidores de la ciudadanía española de la que formamos parte, y queremos una Administración que, huyendo de la retórica, realmente esté al servicio de ella y que sea moderna, eficaz, eficiente y esté prestigiada y legitimada por la sociedad española.

Por ejemplo, pienso que hay que tomar medidas para evitar la burocratización excesiva (lesiva casi siempre para la ciudadanía); en determinados supuestos evitar la ineficiencia de los mecanismos de provisión de algunos servicios públicos; quizás hay que promover sistemas de provisión flexibles, separando las funciones de financiación y de producción de servicios, lo que permite introducir condiciones de mercado y fomentar la competencia entre proveedores, sin privatizar los servicios, ya que éstos pueden permanecer siendo públicos.
También hay que perfeccionar el proceso de asignación de los recursos públicos, de modo que se pueda efectuar una revisión periódica de sus prioridades y ámbitos de actuación, con criterios de evaluación claros que permitan establecer el umbral de las políticas de igualdad. Para ello, el análisis de políticas públicas debería adquirir mayor importancia, como debería tenerla también la incorporación habitual para los Gestores de desarrollar los mecanismos de evaluación y control de gestión, y de pautas flexibles de organización y de métodos de trabajo orientados a la consecución y medición de resultados.

El modelo de Administración deseable debería hacerse factible por la combinación de las prácticas gestoras y la implementación de acciones de cambio a nivel •micro", con planes de acción o de trabajo que tengan como objetivos mejoras inmediatas de resultados concretos y medibles, y que puedan servir como efecto-demostración para las restantes organizaciones. Las innovaciones legislativas han sido importantes, algunas quedan por traducirse a la práctica, pero seguimos creyendo que sla Administración no se cambia por Decreto. y hay que enfatizar mucho más la posibilidad de los cambios obtenidos por la promoción de nuevos sistemas de dirección pública que hagan, sobre el papel cotidiano de funcionamiento y de resultados de las organizaciones, que la función directiva sea más moderna para la mayor eficacia y eficiencia de las administraciones públicas, para situarnos, comparativamente, en posiciones similares a las administraciones más avanzadas de nuestro entomo.
- Inspector General de Servicios de la Administración Pública, MAP.

'El concepto reformas, en términos generales, debe entenderse como el conjunto de los cambios normativos que superen los obstáculos que entorpecen o frenan la adaptación del aparato administrativo y gestor (de las Administraciones) a las nuevas y devenidas circunstancias políticas, culturales y socio-económicas, además de referirnos a las medidas a adoptar para modemizar las prácticas gestoras, que como esfuerzo permanente o continuo permitiera la adecuación de las características de los servicios públicos y de los sistemas de gestión de las organizaciones públicas a las posibilidades ofrecidas por el desarrollo social y tecnológico.

2 Aunque, obviamente, no se deba circunscribir exclusivamente el concepto de profesionalización. a las erelaciones o interferencias producidas entre el ámbito político y el ámbito de gestión o administrativo.

"Como es conocido, las más recientes han sido la ley 50/1997, de 27 de noviembre, del Gobiemo, y la ley 6/1997, de 14 de abril, de Organización y Funcionamiento de la Administración General del Estado (LOFAGE).

4 En el cierre de estas lineas me llega información del principio de acuerdo alcanzado entre el Ministerio de Administraciones Públicas y los principales sindicatos de funcionarios sobre los contenidos del Estaruto, que se incluirán en un Proyecto de Ley en los próximos meses. El hito que supone la aprobación del Estatuto supongo que será aprovechado por las fuerzas políicas para alcanzar el máximo consenso entre ellas, a fin de que consigamos una Norma moderna con vocación de perdurabilidad, que profundice en la profesionalización de las administraciones, que enmarque y permita desarrollar las relaciones laborales especiales de los empleados públicos bajo el manto de los principios constitucionales, que ayude a conseguir niveles más altos de motivación y calidad en el trabajo desempeñado, que permita una mayor au- tonomía y flexibilidad para los directivos de línea en la gestión de los recursos humanos, y que pueda convertirse en un marco duradero legal que sirva a todos los gobiernos y órganos directivos que dirijan cualquiera de las administraciones de su ámbito competencial.

5 Piénsese que con anteriores gobjernos del PSOE se había enunciado, siquiera intencionalmente, $(y$, al parecer, no se pudo llegar ni a concordar sus contenidos en el propio nivel interno gubemamental o de partido, ni por tanto a materializar los proyectos en estudio) un epaquete. de cambios legislativos que incluían una ley de organización de la administración, una ley de gobierno, y un estatuto de funcionarios que diera respuesta a lo establecido constitucionalmente. Se promulgó, no obstante, la Ley de Régimen Jurídico de las Administraciones Públicas (Ley 30/92, de 26 de noviembre).

6 Parafraseo a Michel Crozer, coincidiendo básicamente con lo expuesto en su libro No se cambia la sociedad por Decreto, al señalar que también ta administración no se cambia por decreto.

- Expresión que le oi decir, textualmente, a un líder de opinión asiduo a tertulias radiofónicas, que no quiero ahora avergonzar públicamente.

${ }^{8}$ Conviene no olvidar que órganos directivos (en términos legales) son desde el Subsecretario a Subdirectores Generales o puestos similares, siendo ésta una reforma innovadora de la LOFAGE, todavía insuficientemente valorada en su potencialidad para poder perfeccionar los sistemas de dirección pública que deben incidir decisivamente en el mejor funcionamiento de las organizaciones. En términos organizativos y gerenciales, se consideraria directivos también a numerosas personas que ocupan puestos de trabajo en los que se apoyan los Gestores para dirigir sus organizaciones, especialmente a los responsables de unidades periféricas. 
9 Por cieno, muy poco o mada estudiadas por sociólogos de la administración públicar, siendo, paradójicamente a mi modo de ver, potencialmente muy interesante el campo del estudio de la opinión que tate intemamente y la comunicación informal en el seno de las singulares organizaciones públicas.

${ }^{19}$ Cuando citamos a las administraciones públicas estaremos mencionando a ta globalidad de las mismas, en sus diversos ámbitos territoriales (administración local, au. tonómica y la General del Estado), y dentro de cada una de ellas hay que convenir que existe una alta heterogeneidad que, de conocerse, rompería el arquetipo social de referisse a ta Administración Pública como si de un todo- uniforme se tratase, sin cabida a los matices.

"Cuando cite principios tales como la eficacia y la eficiencia. lo haré sabiendo el alcance de dichas palabras. A veces, el abuso de las mismas podría convertirse en un recurso (o conjuro) para inmunizar a quien las pronuncia, que no se vería obligado a dar orras justificaciones de su utilización. Dichos conceptos no serán mera retórica si conseguimos que, efectivamente, puedan evaluarse, medirse, controlarse. ese mide habitualmente, de forma rigurosa, la eficiencia de cada organización pública?, dlo hacen sus directivos?, ctrabajan los Gestores, sus organizaciones, con definición y establecimiento de objetivos de gestión u operativos, no necesariamente presupuestarios?, ¿qué nivel de participación existe de los directivos en su conformación?, ¿cómo se incentiva su consecución?, ¿cómo se siguen y evalúan la gestión y los resultados?, ¿estamos interesados desde las administraciones en conocer taxativamente si se puede hacer más de lo que hacemos con menos recursos? La eficacia y la eficiencia servirán como conceptos si son útiles en las prácticas directivas, si convenimos que deben semos útiles, si convenimos que estamos desarrollando principios constitucionales, si establecemos que no deben ser detra muerta. en su aplicación.

1'. Son numerosos los procesos de reformas iniciados en los últimos años en numerosos países: los más significativos serian Estados Unidos 1993, Italia 1993, Reino Unido 1986, Francia 1989 (aunque continúe), Suecia 1984 (y continúa con nuevos proyectos), Dinamarca 1985, Holanda 1980, junto a otras reformas en Canadá, Australia, Irlanda y Nueva Zelanda, de años más recientes; examinando todas esas experiencias del exterior, podría decirse que las reformas en el mundo de las burocracias se han justificado por causas más o menos similares en cada país: a) búsqueda del binomio seguridad/flexibilidad; b) mayor autonomia en la gestión; c) laboralización del empleo público; d) mayor responsabilidad en la gestión de los servicios públicos, y transferencia de atribuciones a los directivos de línea; e) modificaciones en el ámbito de diseño gubernamental; f) cambios en la estructura ternitorial y mayor descentralización; g) reestructuraciones globales en el sector público; $h$ ) insatisfacciones sociales muy conflictivas.

1 Como, por ejemplo, devino con algunas políticas de recursos humanos, como las asignaciones del llamado complemento de productividad, sobre el que ha existido gran confusión en su aplicación, y que innovado como medida para evaluar el desempeño de los empleados, en realidad sólo ha servido, en una mayoría de organizaciones, para la retribución de emayor dedicación horaria. a determinados grupos profesionales, y muchas veces sin criterios objetivos de reparto; o lo que sucedió en muchas organizaciones con la incorporación de las nuevas tecnologías informáticas, telemáticas o electrónicas, que todavia no han derivado en la implementación de su tremendo potencial, habiéndose convertido en un instrumento legitimador de politicas gestuales (de •moda*) o incrementalistas, que, devenian en un fin en sí mismas, en lugar de dar importancia a la búsqueda de obtención de mejores resultados en la gestión, como podria haber sucedido con la informatización y agilización de trámites de expedientes en beneficio del ciudadano (la egestión por pantalla. podría ser un buen camino para la reducción del papeleo burocrático, por ejemplo).

${ }^{14}$ Los Planes coordinados por el Ministerio de Administraciones Públicas, con técnicas análogas a la edirección por objetivos, fueron refrendados por un Acuerdo de
Consejo de Ministros, lo que le conferian (asi se visualizó gestualmente) cienta verosimilitud en su implementación. Lo cierto es que fue más el ruido que las nueces y de dichos Planes no se sustanciaron innovadores avances que renovaran las técnicas de gestión pública. Las organizaciones que estaban en estadios avanzados de gestión continuaron estándolo y pocas más renovaron el acervo gestor. Es verdad, no obstante, que se extendió la necesidad de desburocratizar. la gestión, pero, al mismo tiempo, quizás con voluntarismo y buena fe, por supuesto, se experimentaron algunas práaicas de gestión que eran copia. exaca de lo que servia al ámbito privado, lo que, a mi juicio, constinye un error, en la medida que, si se fracasa en su implantación, se añaden obstáculos y mayores resistencias para volver a intentarlo con nuevas experimentaciones. Como se ha señalado en este articulo, el esfuerzo debe encaminarse a construir el paradigma de agestión pública., ensamblando, haciendo compatible la aplicación potente del Derecho Público y el management, analizando lo que se utilice en la empresa privada pero, sólo, para, con ojos críicos, adaptarlo o reinventando lo que atane a la esfera pública.

1) Ni el Presidente ni el Vicepresidente, contrariamente a lo que por ejemplo se ha hecho en el Reino Unido, Francia o en Estados Unidos, lideraron en la práctica, que se conozca públicamente, ni encomendaron acciones de reformas administrativas o de gestión pública, sin lo cual pocos proyectos pueden salir adelante, dada la habitual confrontación horizontal entre Ministerios para estos procesos de cambio.

${ }^{16}$ Es paradigmática la aversión a nuevas técnicas que existe en el sector público, a diferencia de lo que sucede en el sector privado, no fomentándose, en general, a que los funcionarios cumplan objetivos (ni a definir éstos de forma específica u operativa) o a que los gestores asuman riesgos de gestión (innovar)

"Por ejemplo, aun sabiéndose por casi todo el mundo que los sistemas de provisión de puestos de trabajo están, en la práctica y en términos generales, bastante perveridos, no se explica más que por esa patrimonialización. que no se hayan reformado los criterios sobre nombramientos o los concursos de provisión de puestos, o que se haya impedido u obstaculizado la implantación de sistemas de evalua. ción de rendimientos profesionales de los individuos (evaluación del desempeño) 0 simplemente desarrollar más (otorgándole rigor y credibilidad al proceso de entrevistas, por ejemplo) los sistemas de selección basados real y no nominalmente en la capacidad y en el mérito profesional.

${ }^{13}$ En la práctica, no hay más que preguntarse ¿en qué se ha aplicado y para qué sirvió la Ley $22 / 93$, de 28 de diciembre, de reforma del régimen jurídico de la función pública? (Los llamados eplanes de empleo.), csirvió para promover las jubilaciones anticipadas?, ¿sirvió para la redistribución de efectivos excedentarios entre organizaciones públicas?

${ }^{19}$ En algunas organizaciones, desde el ámbito directivo, se hacían lecturas rígidas y no dinámicas de lo previsto por la propia Ley de Procedimiento Administrativo, crite. rios que obstaculizaban la aplicación de nuevas prácticas de gestión deducidas de más modernas interpretaciones sobre determinados aspectos tecnológicos, relativos a las nuevas tecnologias de la información.

3) La búsqueda de la mejor percepción social de ciertas medidas políticas, junto a los casos de corrupción más conocidos, seguramente, por poner un ejemplo, justificarían que los parlamentarios consensuaran la aprobación de la Ley de Contratos del Estado, que, aunque sea en voz baja y en la cafetería , muchos directivos critican por la extrema rigidez y coste que supone su aplicación estricta. Este autor escuchó en un seminario universitario a un político catalán del actual Govern de la Generalitat de Catalunya criticar el contenido de las modificaciones de dicha Ley, con rigor y suficientes argumentos de egestión pública, y autocriticarse como político por dar su apoyo a tal norma. 


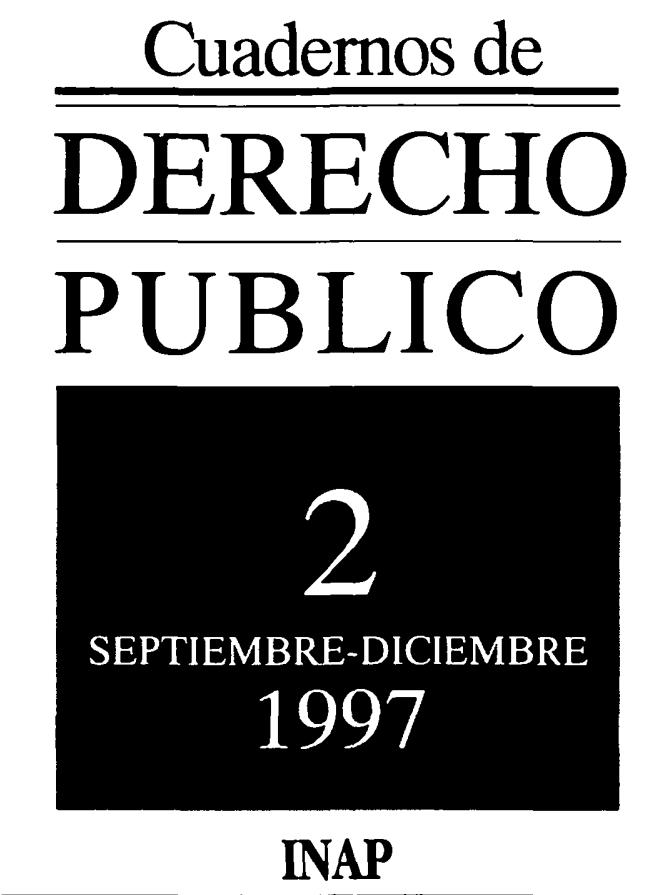

\section{Instituto Nacional de Administración Pública}

Nueva publicación editada por el Instituto Nacional de Administración Pública, los Cuadernos de Derecho Público, dedicada a los estudios y análisis relativos a la organización y funcionamiento del Estado desde una perspectiva global, interdisciplinaria, que aspira como tal publicación, integradora y rigurosa en sus planteamientos, a abrirse un espacio en el marco de la publicistica actual.

\section{CONSEJO DE REDACCIÓN}

Presidente: José Luis Meilán Gil. Vocales: Enrique Arnaldo Alcubilla, José Luis Cascajo Castro, Francesc de Carreras Serra, Ignacio Díez Picazo, Germán Fernández Montalvo, Tomás González Cueto, Lourdes Máiz Carro, Alejandro Menéndez Moreno, Juan Antonio Ortega Díaz-Ambrona, José Luis Piñar Mañas, María Rosa Ripollés Serrano, Luis Ignacio Sánchez Rodríguez, José Antonio Souto, Carles Viver i Pi-Sunyer, Tomás S. Vives Antón.

\section{Director}

Luis Aguiar de Luque

\section{Secretario}

Ricardo Blanco Canales

\section{Coordinación}

Centro de Publicaciones del INAP

\section{Edita:}

MINISTERIO DE ADMINISTRACIONES PÚBLICAS Instituto Nacional de Administración Pública ISSN: 1138-2848 NIPO: 329-97-007-1

Depósito Legal: M-35.142-1997

Imprime: Solana e Hijos, A.G., S.A.

San Alfonso, 26. 28917 Madrid

\section{Precios:}

\section{Suscripciones y Administración:}

Instituto Nacional de Administración Pública Publicaciones Periódicas

Atocha, 106. 28012 Madrid

Teléfono: 3493235 